\title{
Em busca de leitores inábeis: a luta popular pela expansão do Ensino Secundário e o ensino de História nas décadas de 1950-1970
}

\author{
Diogo dos Santos Brauna* \\ Rafael Lopes de Sousa** \\ Luiz Antonio Dias ${ }^{* * *}$
}

\section{Resumo}

O processo de ampliação das oportunidades escolares em todos os níveis de ensino modificou consideravelmente a estrutura do sistema de educação no Brasil, durante todo o século XX. O objetivo deste artigo é discutir as lutas pela expansão do Ensino Secundário à luz da Lei n. ${ }^{\circ}$ 4024/1961 e seus impactos no ensino de História, principalmente na produção de livros didáticos, objeto complexo e que tem cumprido um papel fundamental na consolidação do sistema educacional brasileiro. $\mathrm{O}$ artigo inventaria as políticas e as transformações socioculturais que redimensionaram o papel do Estado no atendimento das demandas sociais, com destaque para a educação do Ensino de História no contexto da urbanização e modernização da sociedade brasileira pós revolução de 1930 e analisa os impactos na produção didática do período.

Palavras-chave: educação, luta popular, expansão do ensino médio, ensino de história.

* Mestre em Educação (PUC/SP). Professor da Universidade Santo Amaro (UNISA).dbrauna@gmail.com

** Doutor em História Social (Unicamp/SP). Professor do mestrado interdisciplinar em ciências humanas da Universidade de Santo Amaro (UNISA). canoeiros2008@gmail.com

*** Doutor em História Social (UNESP/Assis). Professor Doutor no Departamento de Historia da PUC-SP e Professor da Universidade de Santo Amaro. luizhistoria@yahoo.com.br 


\title{
In search of unskilled readers: the popular stru- ggle for the expansion of Secondary Education and the teaching of History in the 1950-1970s
}

\begin{abstract}
The process of expanding school opportunities at all levels of education considerably modified the structure of the education system in Brazil and São Paulo, throughout the 20th century. The purpose of this article is to discuss the struggles for the expansion of Secondary Education in the light of Law No. 4024/1961 that consolidated the National Education Guidelines and Bases. The article would invent the socio-cultural policies and transformations that reshaped the role of the State in meeting social demands, with an emphasis on education in the context of urbanization and modernization of Brazilian society after the 1930 revolution.
\end{abstract}

Keywords: education, popular struggle, expansion of secondary education, teaching of history

\section{En busca de lectores no calificados: la lucha popu- lar por la expansión de la Educación Secundaria y la enseñanza de la Historia en la década de 1950- 1970}

\section{Resumen}

El proceso de ampliación de las oportunidades escolares en todos los niveles educativos ha cambiado considerablemente la estructura del sistema educativo en Brasil a lo largo del siglo XX. El objetivo de este artículo es discutir las luchas por la expansión de la Educación Secundaria a la luz de la Ley $N^{\circ}$ 4024/1961 y sus impactos en la enseñanza de la Historia, principalmente en la producción de libros de texto, objeto complejo que ha jugado un papel fundamental. papel en la consolidación del sistema educativo brasileño. El artículo inventó las políticas y transformaciones socioculturales que redimensionaron el papel del Estado en la satisfacción de las demandas sociales, con énfasis en la formación de la Docencia de Historia en el contexto de la urbanización y modernización de la sociedad brasileña después de la revolución de 1930 y analiza los impactos producción didáctica de la época.

Palabras clave: educación, lucha popular, expansión de la educación secundaria, enseñanza de la historia. 


\section{Introdução}

A elaboração e a aprovação da primeira Lei de Diretrizes e Bases da Educação Nacional (LDB 4.024/61) são frutos de transformações que começaram a se desenrolar no setor educacional nas décadas que compreendem os períodos de 1930 a 1950, quando se verifica uma maior participação do Estado para atender as demandas sociais do momento. Nesse contexto vários projetos educacionais disputavam espaço e a atenção dos governos. Alguns defendiam a ideia de uma educação escolar para todos como principal vetor do desenvolvimento econômico e social da sociedade; outros eram partidários de uma educação escolar separada com ensinamentos específicos para as elites. Essa disputa redimensiona os horizontes das políticas educacionais que serão adotadas para a educação brasileira nas décadas posteriores.

A concentração da população nos grandes centros urbanos fez prosperar a idéia de uma educação inclusiva, defendida por setores da elite industrial, como exigência indispensável para melhor qualificar o trabalhador para as novas e desafiadoras funções do trabalho fabril. Ocorre que até a década de 1940 a indústria brasileira estava quase que integralmente concentrada na região sudeste, não tinha, portanto, um projeto claramente definido para a formação técnico educacional de todos os brasileiros. A fim de fazer frente aos reduzidos investimentos da burguesia na formação e qualificação de uma nova mão-de-obra, o Estado assume a função de principal financiador das políticas educacionais da nação.

\section{O Estado como Provedor da Educação}

A agenda educacional brasileira da década de 1930 em diante é um compromisso cada vez mais visível do Estado. Nesse contexto o documento conhecido como Manifesto dos Pioneiros da Educação Nova tornou-se base política e de modernidade que alicerçaria a educação da sociedade brasileira. A educação pública é doravante compreendida como responsabilidade do Estado, que garantiria uma escola única para a população brasileira, ou seja, se 
a educação passa a ser um direito de todos, portanto, as classes populares excluídas das escolas privadas, teriam uma escola comum às instituições privadas com condições de formação igualitária.

Nessa ampliação dos serviços oferecidos pelo Estado à população a Constituição de 1946 exerceu papel de destaque ao defender, como medida necessária para a modernização da educação brasileira, em seu artigo 168 inciso II e III a obrigatoriedade e gratuidade do ensino bem como propor que a educação é "direito de todos e será dada no lar e na escola, deve inspirar-se nos princípios de liberdade e nos ideais de solidariedade humana" [destaque nosso]. Esses princípios guiaram a luta pela expansão do Ensino Secundário mobilizando diferentes forças sociais conforme salienta (Spósito, 1984).

As direções imprimidas ao crescimento urbano, suas distorções e a consequente deterioração dos níveis de vida das classes populares, aliadas à crise política instaurada durante a década de 30 e anos seguintes, possibilitaram a emergência de um amplo quadro de descontentamento social e de mobilização destas massas que, inegavelmente, interferiu no sentido das transformações por que passou o ensino público [...] A aspiração por melhores oportunidades educacionais, parte do conjunto de reivindicações de bens de consumo coletivo urbano, se por um lado expressava mais uma dentre as numerosas solicitações dos moradores de vilas periféricas destituídas desses benefícios, por outro, revestia-se de características que a tornavam diferente dos pedidos de água encanada, luz, policiamento e transporte. Enquanto grande parte destas demandas incidia sobre a obtenção de melhorias que provocariam em curto prazo a elevação da qualidade de vida das populações subalternas ou, ao menos, tornariam mais atenuadas as suas dificuldades de sobrevivência, o acesso à escolaridade desdobrava-se em projetos esboçados em longo prazo que buscavam operar mudanças na situação social desses setores. [...] Dessa forma, esses segmentos desprivilegiados acreditavam, mediante o ingresso de seus filhos em estabelecimentos mantidos pelo Estado, os seus anseios relativos à ascensão social poderiam ser melhor concretizados. (SPÓSITO, 1984, p. 211-212)

Pode-se dizer, então, que a luta pela expansão da escola pública está diretamente relacionada com o crescimento demográfico, com a industrialização e as transformações socioculturais da socie- 
dade brasileira após revolução de 1930. Mudanças foram introduzidas nas relações de produção, antes marcadas por uma estrutura oligárquica. O modelo agrário-rural cedeu lugar a uma economia industrial-urbana e a concentração cada vez maior da população em grandes centros tornou inevitável a ampliação da escolarização. Essas transformações descortinaram as exigências para a modernização da sociedade e fermentaram as lutas para a ampliação do ensino para amplos setores da população. A educação deixa, pois, de ser vista como privilégio social para ser percebida como quesito fundamental e necessário à formação e integração do indivíduo em sociedade. A primeira conquista alcançada foi o aumento dos índices de matrículas que permitiu o acesso de amplos setores das classes populares à escola pública.

O crescimento urbano e a deterioração dos níveis de vida, associados às mudanças políticas após a década de 1930, especialmente com o fim do Estado Novo, bem como a consolidação de um projeto de abertura política nos anos seguintes, pavimentou os caminhos para a mobilização e a interferência dos trabalhadores urbanos nas políticas educacionais. Nas décadas seguintes, isto é, nos anos de 1940 e 1950, o número insuficiente de escolas públicas e privadas para atender as novas demandas da sociedade fez aumentar as pressões populares por acesso aos bancos da escola, principalmente no ensino secundário. Pressionados por suas bases eleitorais os políticos encomendam estudos e colocam em prática uma série de medidas que visam ampliar a oferta de vagas nas escolas para a população. Conforme explica Spósito (1984)

[...] durante os anos de 1957 e 1958, o Poder Público pôs em prática uma série de soluções possibilitando a rápida proliferação dos cursos ginasiais da cidade. As medidas adotadas nessa ocasião revestiram-se de grande importância porque ofereceram à Administração Pública as soluções necessárias à continuidade do crescimento da rede, em anos posteriores, ao se acentuar a tendência à generalização das oportunidades de acesso à instrução secundária [...] o Poder Público viu-se na contingência de responder, simultaneamente, às necessidades de crescimento do ensino elementar e ginasial (SPÓSITO, 1984, p. 29-30) 
A expansão da rede de ensino público, particularmente a do Ensino Primário que ocorreu durante a primeira república foi viabilizada por uma série de medidas administrativas que objetivavam formar uma rede extensa e organizada através das escolas isoladas e dos Grupos Escolares explicitando, assim, um processo de democratização do acesso que visava atender à crescente população urbana, que procurava novas oportunidades de trabalho principalmente em São Paulo. Em outras palavras, a escolarização crescia para atender os interesses e expectativas dos novos segmentos sociais que emergiam por conta da industrialização.

A solução encontrada para viabilizar o atendimento das necessidades escolares no início do período republicano, foi a redução para 4 anos de duração de estudo dos Grupos Escolares, duas décadas mais tarde, em 1928, ocorreu a introdução do $3^{\circ}$ período, com horário reduzido para 3 horas. Na década de 1940, o Estado e a Prefeitura de São Paulo "passam a agir em conjunto visando suprir deficiências na oferta de matrículas da escola elementar no Município da capital" (SPÓSITO, 1984, p. 35). Assim, ao privilegiar o ensino primário na Primeira República, o Estado abre espaço para as tradicionais características seletivas do estudo, uma vez que a inexistência de outros estabelecimentos públicos de ensino impedia que a população sem recursos frequentasse a escola.

Entre os anos de 1892 e 1958 foram construídos 91 ginásios na cidade de São Paulo. Após 1945, o foco prioritário desses ginásios foi o atendimento dos cursos noturnos. Essa nova modalidade de estudo evidenciou as contradições do prolongamento da escolarização, ou seja, o aluno pobre tinha de combinar uma jornada extenuante de trabalho e depois disso conseguir um bom desempenho nas atividades escolares para não ser expurgado do sistema de ensino. Outros fatores contribuíram para o agravamento do problema, entre eles podemos destacar: os exames admissionais que segregava uma parte considerável dos candidatos às séries iniciais e a precariedade das instalações para o corpo docente e administrativo. 
Em São Paulo, a luta pela expansão do ensino público ganhou um novo impulso na década de 1950. Nesse período diversos movimentos de bairro foram criados. Essas mobilizações sociais ganharam espaço na imprensa que passou a acompanhar in loco as queixas e reivindicações das associações de bairros, comissões de pais e estudantes, que pressionava e cobrava respostas do poder público para a ampliação da escola pública. As respostas dos agentes políticos eram geralmente vagas e generalistas:

[...] as condições orçamentárias parcas em recursos destinados aos equipamentos sociais, grande parte das demandas a eles dirigidas não era atendida ou realizava-se de forma precária. Nessas circunstâncias, eram intensas as disputas existentes entre as lideranças que procuravam demonstrar capacidade de atendimento às solicitações populares, buscando, ao mesmo tempo, os proventos políticos que garantissem maiores posições de prestígio e poder. É fato inegável que todos esses processos acabaram por atingir de forma decisiva não só o ensino ginasial em sua expansão, como, também, o curso elementar público, delimitando as direções percorridas pelo sistema escolar da Capital neste período. (SPÓSITO, 1984, p. 212)

Em sua rápida ascensão política, que começou na década de 1950 quando ocupou uma cadeira na Assembleia Legislativa Estadual, Jânio Quadros já via nas causas educacionais uma plataforma de mobilização para suas campanhas. Talvez, por isso, realizava incursões frequentes à periferia da cidade de São Paulo e lá discursava em defesa das propostas e reivindicações da população. Em seus dois primeiros anos, como deputado estadual conseguiu protocolar cinquenta e oito projetos de lei, sendo que, vinte deles, tratavam da expansão do ensino público.

As primeiras disputas pela expansão do ensino público ocorreram no início de 1951. Ao perceber a importância eleitoral dessa pauta, os vereadores da cidade agiram imediatamente para intervir no processo de escolhas dos bairros que receberiam prioridade para a construção ou instalação de novas unidades escolares. Jânio Quadros percebeu também essa importância e adota a pauta educacional como uma de suas principais bandeiras política. A rápida ascensão de 
Jânio Quadros ao governo do Estado, no final de 1954, alterou profundamente a política de expansão, que se estendeu também para as periferias por meio do estreitamento das relações com as associações de bairros e comissões de moradores que representavam a população local. Em 1956, seu governo um projeto de lei para criar os ginásios também nas zonas periféricas em caráter de urgência.

A expansão dos ginásios para a periferia serviu de estímulo para que outros bairros também buscassem no governo de Jânio apoio para a criação de novas escolas. De acordo com Spósito (1984, p. 223), Jânio soube tirar proveito dessa situação e assim se transformar no grande interlocutor dos interesses populares para o processo de expansão da rede de Ensino Ginasial. Seus interesses políticos tornavam-se assim:

[...] mais urgentes em virtude da proximidade das eleições, imprimindo nova força na criação dos ginásios em bairros distantes da cidade. Naquela conjuntura, mais do que em momentos anteriores, seria preciso atender a algumas expectativas das massas urbanas em troca de seu apoio eleitoral. O Diretor do Departamento de Educação, nesse período, recorda a 'furiosa criação de secções', muitas vezes em poucas horas. Frequentemente recebia determinações da Chefia do Gabinete do Governador para que providenciasse a instalação de ginásio em bairros previamente designados; desse modo, o líder populista poderia presidir à sua inauguração perante os moradores da localidade a ser visitada. (SPÓSITO, 1984, p. 239)

A expansão do ensino serviu como grande plataforma política e eleitoral para Jânio Quadros. Nesse processo de expansão do Ensino Primário e Secundário, seus defensores tiveram de se confrontar com forças contrárias à expansão. Parte significativa desses setores via a expansão como uma ameaça e defendiam uma política de melhorias dos estabelecimentos existentes, dificultando assim o acesso popular à escola. Talvez por isso, os decretos aprovados na Assembleia Legislativa de São Paulo, Vale autorizava a criação dos ginásios, mas não garantiam recursos para a sua manutenção. Ao perceber a armadilha as comunidades periféricas mobilizaram-se em busca de alternativas para reunir recursos e garantir a manutenção dos estabelecimentos por meios próprios. 
Apesar das diversas deficiências, da morosidade legal para os novos ginásios fossem implantados, a população, ainda assim, percebia as significativas transformações ocorridas no ensino oficial. No final dos anos 1950 e início dos anos de 1960, a expansão do ensino público tomaria novos rumos com a tramitação do projeto de lei pelo Congresso Nacional e os debates que deram origem a Lei de Diretrizes e Bases no 4.024 de 1961, sancionada em 20 de dezembro, na gestão do Presidente João Goulart.

O projeto tramitava desde 1948 através de imposição legal determinada pela Constituição de 1946, ocasião em que foi “apresentado um projeto de lei que determinava as Diretrizes e Bases da Educação Nacional, [...] oriundo de uma comissão de educadores e apresentado ao Congresso pelo Governo de Eurico Gaspar Dutra". No entanto, a discussão sobre o referido projeto havia sido restrita a política interna do Congresso. Somente no final da década de 1950, após "ataques de deputados à figura de Anísio Teixeira e sua consequente defesa por seus partidários”, o tema passa a ser veiculado pelos jornais e revistas da época ganhando, assim, novas dimensões no âmbito civil.

Alguns dispositivos geraram bastante controvérsia, principalmente aqueles que diziam respeito ao financiamento da educação, à liberdade de ensino e direito à educação, mobilizando diversos setores sociais que até então não haviam participado diretamente da luta pela expansão, como o movimento estudantil, o movimento sindical, partidos políticos e intelectuais da Universidade de São Paulo.

A mobilização que configurou a luta pela expansão do ensino público e a consequente entrada de novos grupos sociais no Ensino Secundário, especialmente as classes populares, transformaria profundamente o ensino brasileiro e também a produção de livros didáticos. O controle da produção e circulação já era uma prática bastante antiga, porém, desde os anos 1930, os governos haviam demonstrado uma preocupação especial com o livro didático através de comissões, como a Comissão Nacional do Livro Didático (CNLD), instituída pelo Decreto-lei no 8460 de 26 de dezembro de 
1945 em reformulação ao Decreto-lei no 1006 de 30 de dezembro de 1938, "estabelecendo as normas para o uso do livro didático em sala de aula, bem como orientações para o professor, critérios para a elaboração e autorização das edições didáticas para serem adotadas pelas escolas em território nacional", ou mesmo pela Campanha do Livro Didático e Manuais de Ensino, instituída por Anísio Teixeira na década de 1950 (RIBEIRO JR, 2007, p. 34).

Do ponto de vista do ensino de História, Fonseca (2011) salienta que nos anos de 1950 e 1960 não ocorreram grandes mudanças que afastassem as práticas e concepções tradicionais, ou seja, apesar das transformações empreendidas através das reformas educacionais e também com a introdução dos novos grupos heterogêneos na rede de ensino, houve uma significativa permanência em alguns pontos comuns que identificavam o ensino de História. Por exemplo, a ênfase demasiada nos "fatos políticos" e a abordagem biográfica centrada na trajetória de vida de pessoas consideradas ilustres ou "brasileiros célebres", que incluíam inclusive alguns personagens dos governos militares (FONSECA, 2011, p.55-56).

\section{A Metodologia de Ensino do Livro Didático de História no Ensino Público}

Com o movimento de expansão o ensino público havia se modificado consideravelmente, principalmente em relação à composição de seu público. Neste sentido, um dos impactos da expansão e do ingresso de um público cada vez mais heterogêneo na rede de ensino, foi na composição das disciplinas escolares ${ }^{1}$ e na produção de materiais didáticas, sobretudo nos livros didáticos. Deste modo, torna-se fundamental compreender como o ensino de História e algumas produções corresponderam a estas transformações significativas da educação pública e quais expectativas os livros didáticos buscaram atender.

Para uma maior definição do conceito de disciplina escolar, vide CHERVEL, André. 1990. História das disciplinas escolares: reflexões sobre um campo de pesquisa. Teoria \& Educação, Porto Alegre, vol. 2, p. 177-229. 
As novas demandas alterariam, pois, as estruturas das obras, não apenas em seu projeto gráfico, mas também na proposta da relação do leitor com o texto, uma vez que os livros passam a direcionar cada vez mais a sua escrita para os estudantes. Nesta perspectiva, Chartier (1990) argumenta que:

[...] o leitor é, sempre, pensado pelo autor, pelo comentador e pelo editor como devendo ficar sujeito a um sentido único, a uma compreensão correcta, a uma leitura autorizada. Abordar a leitura é, portanto, considerar conjuntamente, a irredutível liberdade dos leitores e os condicionamentos que pretendem refreá-la. Esta tensão fundamental pode ser trabalhada pelo historiador através de uma dupla pesquisa: identificar a diversidade das leituras antigas a partir de seus esparsos vestígios e reconhecer as estratégias através das quais autores e editores tentavam impor uma ortodoxia do texto, uma leitura forcada. Dessas estratégias, umas são explícitas, recorrendo ao discurso (nos prefácios, advertências, glosas e notas), e outras implícitas, fazendo do texto uma maquinaria que, necessariamente, deve impor uma justa compreensão. Orientado ou colocado numa armadilha, o leitor encontra-se, sempre, inscrito no texto, mas, por seu turno, este inscreve-se diversamente nos seus leitores. (CHARTIER, 1988, p. 123, grifo nosso)

Compreender o tipo de leitor que os livros visavam e quais estratégias foram empregadas para conformar certo conhecimento, pode contribuir para a investigação de concepção de História e Ensino de História que foram veiculadas no período, bem como suas contribuições para a História da Educação Brasileira.

Tomando como exemplo a publicação da obra História do Brasil, do autor Antônio José Borges Hermida², os manuais publicados após os anos de 1960, ao mesmo tempo em que conservaram

2 Hermida foi professor do prestigiado Colégio Pedro II. Sua obra tornou-se uma das mais vendidas no período de 1950 a 1970. O livro História do Brasil circulou no mercado editorial por aproximadamente 50 anos. As edições mais antigas localizadas datam do final dos anos de 1940 e as mais recentes dos anos de 1990, ou seja, percorreram um longo período tanto da história política e educacional do país quanto do mercado editorial, sendo que em 1951 o livro já atingia a impressionante marca de 21 edições. 
os textos-base, apresentaram intervenções editoriais acentuadas. As produções que circularam ao longo das décadas de 1960 e 1970 buscaram uma comunicação mais próxima com alunos e professores, porém sem um prefácio nas páginas iniciais.

Na década de 1970, com a instituição da reforma 5.692/71, diversas mudanças na estrutura do ensino interferiram diretamente na composição da obra. Em função da introdução do ensino de $1^{\circ}$ e $2^{\circ}$ graus, que alterou o tempo de escolarização obrigatória de quatro para oito anos, com a união do antigo primário e ginásio; da instituição dos Estudos Sociais no Lugar de História e Geografia e da consolidação das Licenciaturas curtas, com o objetivo de gerar profissionais para as novas demandas da educação pública, o livro sofreu drásticas intervenções editoriais. Destaca-se principalmente a introdução de uma linguagem que se esforçava em ser dialógica. Por exemplo, o texto inicial do Livro História do Brasil 1,trazia como título "A história que você vai estudar" e seguia com a informação de que:

O Brasil foi descoberto e colonizado pelos portugueses.

Até o dia 7 de setembro de 1822, quando o príncipe D. Pedro proclamou a Independência, o Brasil foi colônia de Portugal; é o Brasil colonial que você vai estudar este ano. Tudo começou quando Pedro Álvares Cabral, que viajava para as índias, descobriu a nossa pátria, ao avistar o monte Pascoal, no dia 22 de abril de 1500. (HERMIDA,1971, p. 1)

Nesta nova composição, o texto procurava dialogar com o aluno e colocava em destaque certas palavras que seriam exigidas nos exercícios (descoberto, colonizado, colônia, monte Pascoal), utilizando o itálico como recurso. Somente nos livros publicados após os anos 80 verifica-se a existência de uma nota dos autores intitulada "Aos professores de História", esclarecendo que:

Escritos de acordo com a moderna metodologia do ensino de História, que enfoca esta matéria no conjunto das Ciências Sociais, aos nossos livros, que agora editamos, também para as quatro séries do primeiro grau, muito diferem dos anteriores:

o texto, na linguagem simples e atraente a que sempre recorremos quando escrevemos livros escolares, foi ampliado, até com a inclusão de novos 
tópicos e capítulos, que julgamos da maior importância para a formação da cultura dos nossos estudantes;

os exercícios mais diversificados, sempre escolhidos entre os que melhor atendem à capacidade de reflexão dos alunos, além das páginas de recreação - loterias da História, palavras cruzadas, pesca-palavras - tornam a atividade de verificação de aprendizagem mais agradável e de maior rendimento; melhor apresentação gráfica, com novo elenco de gravuras e mapas, selecionados sob rigoroso critério didático;

a publicação em separado, num caderno especial, dos exercícios e das atividades recreativas, o que possibilita, por anos seguidos, a utilização do mesmo livro-texto, num empenho de todos - editores, autores, professores e autoridades de ensino - de atenderem aos pais de aluno de menor poder aquisitivo.

Finalmente, aguardamos dos nossos colegas, em cuja boa vontade, talento e experiência confiamos, sugestões e reparos, que hão de contribuir para o aprimoramento dos nossos trabalhos, pelo que, antecipadamente, agradecemos. (HERMIDA, 1996, p. 2, grifo nossos)

Especificamente nestas edições, a necessidade de dialogar com os professores surgiu em virtude das mudanças introduzidas na obra, em especial a ênfase "na inclusão de novos tópicos e capítulos" e na separação do caderno de atividades, cuja justificativa recaiu sobre a necessidade de atender aos "pais de aluno de menor poder aquisitivo".

Outra mudança significativa foi a introdução de uma diversidade de imagens como tiras, charges, reprodução de quadros e desenhos próprios, com a finalidade de confirmar aquilo que havia sido dito no texto-base. No entanto, diferente de edições anteriores, as tiras e imagens estilizadas apresentavam um enredo próprio, ainda que se reportassem ao texto-base.

Másculo (2008), citando Kossoy (2003); Briggs\&Burke (2004) e Sevckenko (2001), destacam o grande interesse pelas imagens no século XX. Dentre elas, não apenas o cinema e a televisão, mas também a fotografia teve um papel de destaque, no Brasil, a partir do anos de 1960. Verifica-se, a partir de então, em revistas de grande circulação e enciclopédias ilustradas a ampla utilização de fotografias. Justamente no final dos anos de 1960: 
[...] alguns historiadores e editoras, com motivações diferentes, apostaram na ampla utilização da imagem como recurso didático nos livros escolares que lançariam nos primeiros anos da década de 1970. Seja pelas páginas altamente ilustradas dos livros didáticos da Coleção Sérgio Buarque de Hollanda, pelos slides do História Fundamental do Brasil, pelas histórias em quadrinhos dos livros de Julierme ou por outros livros que veremos mais adiante, é certo que um conjunto significativo de imagens estava presente em muitas aulas de história na década de 1970. (MÁSCULO, 2008, p. 134-135)

Assim, as décadas de 1960 e 1970 apresentaram uma preocupação significativa com o uso dos recursos de imagem na produção de livros didáticos. Uma opção utilizada com bastante frequência eram os desenhos e cartogramas, seja com o objetivo de adequar as imagens a um conteúdo específico ou como forma de burlar os direitos autorais.

Os conteúdos também sofreram modificações significativas. Ainda que o texto-base não tenha sofrido alterações estruturais, a forma na qual foram apresentados, ao longo destas duas décadas, sofreu intervenções editoriais que alteraram não apenas sua apresentação, mas também objetivaram um diálogo diferente. Diferentemente das edições dos anos de 1950, estruturadas tal qual rezavam as portarias, nas décadas de 1960 e 1970 as edições da obra História do Brasil apresentavam diversos subitens, fragmentando significativamente a extensão dos textos e permitindo a leitura por blocos. Evidentemente a obra foi modificada em função de um novo público e, consequentemente, um novo perfil de leitores pensado pela editora.

Chartier (1988), tratando das especificidades da literatura de cordel, analisa o trabalho da intervenção editorial e a ideia de adequação de leitura, percebendo que:

Este trabalho de adaptação modifica o texto relativamente ao modo como é apresentado na edição anterior, que serve de cópia para os impressores de livros (populares) e é orientado pela representação que estes têm das competências e das expectativas culturais de leitores para que o livro não é algo familiar. Essas transformações são de três espécies. Encurtam os textos, suprimem os capítulos, episódios ou divagações considerados supér- 
fluos, simplificam os enunciados aliviando as frases das orações relativas e intercalares. Dividem os textos criando novos capítulos, multiplicando os parágrafos, acrescentando títulos e resumos. (CHARTIER, 1988, p. 129130, grifos nossos)

Ainda de acordo com Chartier, esta estratégia visa controlar os conteúdos e torná-los mais facilmente decifráveis por parte de leitores inábeis.A leitura, neste caso, exige sinais de identificação através de intertítulos antecipatórios,de resumos e imagens que são associadas ao texto com o objetivo de produzir certo sentido, funcionando como "protocolos de leitura ou lugares de memória do texto” (CHARTIER, 1988, p. 130).

Tratando dos mesmos conteúdos dos livros que se reportavam aos programas de estudos de 1951, nas décadas de 1960 e 1970 , estes eram apresentados com uma nova roupagem, visivelmente para atender um público diferente. Desta maneira, "As grandes navegações", tornaram-se "pelo mar os homens conheceram o mundo". O "descobrimento" tornou-se "A terra que Cabral descobriu" e o "Íncola" transformou-se em "Brasil, uma mistura de raças”. (HERMIDA, 1971)

Os programas dos anos de 1950 determinavam três pontos para cada Unidade. Desse modo, na Unidade I, eram contemplados "1. As Grandes navegações”; "2. Pedro Álvares Cabral e o Descobrimento", e "3. As primeiras expedições exploratórias". Nos anos de 1970 esta unidade era diluída em 3 capítulos com mais de 30 pontos, que nada mais eram que uma fragmentação do texto em subitens.

O trabalho editorial da CEN foi imprescindível para adequar o livro História do Brasil as demandas geradas pela expansão do ensino público. Ao fazer isto, a editora manteve os textos-base tradicionais de Borges Hermida e, através da intervenção editorial, buscou um diálogo com o aluno e adequar o livro as exigências de mercado, empregando a imagem como recurso.

A opção em apresentar as unidades através de subitens favorecia o trabalho do professor em sala de aula, uma vez que era possível trabalhar uma quantidade específica de subitens do capí- 
tulo por aula(s), sem uma quebra abrupta da leitura de um texto corrido e extenso.

\section{Considerações Finais}

A primeira metade do século XX foi um período marcado pela forte industrialização e pela consequente mudança das características da população brasileira. A crescente urbanização intensificou o crescimento demográfico e incrementou as lutas populares com pautas específicas para a população das periferias. Neste cenário, a educação passa a ser uma das principais pautas das lutas populares, que reivindicam principalmente a criação de vagas e a construção de novas unidades escolares de ensino secundário.

Diversos políticos, entre eles Jânio Quadros, souberam capitanear as demandas educacionais e, assim, atender parcialmente as necessidades da população construindo novas unidades escolares nas periferias. Apesar disso, a garantia das matrículas continuava a ser atendida pelo poder público de forma precária e limitada, isto é, o acesso à escola para população pobre continuava a ser dificultado por meio de diversos estratagemas entre os quais podemos estacar a redução dos turnos de aula.

A produção de material didático para os alunos notadamente o livro didático teve também de se adaptar as novas demandas da expansão, ou seja, seu projeto gráfico foi inteiramente pensado a fim de estabelecer uma relação de proximidade e dependência do leitor. Daí o uso exagerado de elementos visuais, como fotografias e histórias em quadrinhos. Essa estratégia idealiza estudantes e leitores de menor poder aquisitivo e capacidade intelectual e assim controla conteúdos para supostamente torná-los decifráveis aos leitores considerados inábeis pela escola excludente que vigorou no Brasil por praticamente todo o século XX. 


\section{Referências}

CHARTIER, Roger. A história cultural entre práticas e representações. Lisboa: Difel.1988.

Cultura escrita, literatura e História. Porto Alegre: Artmed. 2001.

HERMIDA, Antônio José Borges. História do Brasil 1. São Paulo: Cia Editora Nacional, 1971.

História do Brasil. $5^{a}$ série. São Paulo: Cia Editora Nacional, 1996.

MÁSCULO, José Cássio. A Coleção Sergio Buarque de Hollanda: livros didáticos e ensino de história. Tese de doutorado. São Paulo: PUC-SP. 2008.

MOREIRA, Kênia Hilda. Um inventário: o livro didático de História em pesquisas (1980-2005). São Paulo: Editora Unesp. 2011.

MUNAKATA, Kazumi. Produzindo didáticos e paradidáticos.Tese de doutorado. São Paulo: PUC-SP. 1997.

RIBEIRO, Milton. Planejamento visual gráfico. Brasília: LGE Editora. 2003.

RIBEIRO, Renilson Rosa. Exóticos, infantis e submissos na colônia identitária: as representações dos negros nos livros didáticos de história do Brasil. Revista História \& Perspectivas, Uberlândia, Vol. 38, p. 43-77, Jan/Jun. 2008.

A questão do "outro" e os livros didáticos. In: Revista Fato\&Versões, Vol. 2,n. 4,jul/dez, p.75-88. 2010.

RIBEIRO JR, Halferd Carlos. O sistema de ensino ginasial e livros didáticos: Interpretações da independência brasileira de Joaquim Silva entre 1946 e 1961. Dissertação de mestrado. Franca: UNESP-SP. 2007.

SEVCKENKO, Nicolau. A corrida para o século XXI - No loop da montanha russa. São Paulo: Companhia das Letras. 2001.

SCHWARCZ, Lilia Moritz. O Espetáculo das Raças: cientistas, instituições e questão racial o Brasil 1870-1930. São Paulo: Companhia das Letras. 1993.

SPÓSITO, Marília Pontes. O povo vai à escola. São Paulo: Edições Loyola.1999. 
TOLEDO, Maria Rita de Almeida. 2001. A coleção Atualidades Pedagógicas: do projeto político ao projeto editorial (1931-1981). Tese de doutorado, PUC-SP. 1984.

WARDE, Mirian Jorge. A industrialização das editoras e dos livros didáticos nos Estados Unidos (do começo do século XIX ao começo do século XX). Revista Educação \& Sociedade. Campinas, vol. 32, n. 114, jan/mar, p. 121-135. 2011. 